\title{
Conceptualize Model of Procurement System through ERP
}

\author{
Soubhik Mishra \\ NICMAR, Pune, \\ India
}

\author{
Sameer Jain \\ NICMAR, Pune, \\ India
}

\author{
Lav Kumar Jain \\ NICMAR, Pune, \\ India
}

\author{
Tapaswi \\ Kanchenrla \\ NICMAR, Pune, \\ India
}

\author{
S. Vidyashiny \\ NICMAR, Pune, \\ India
}

\begin{abstract}
The main scope of construction Industry lies with the starting step of conceptualization. ERP system works across Domain, Customer data linking with micro and macro world in construction Industry and to provide full scope for any kind of purchasing behavior of resources. To provide slab, recommendations and data to help employee base in taking sound decision adhering to company's policy. To innumerate and forecast various constraints and possibilities which can influence the procurement in Construction Industry. The adequate follows to the failures in the Construction Real Estate Infrastructure Project (CRIP) Industry such as, lack of managerial experience, Non-use of documentations and relevant available information. The study has also got us to develop that transparency, automation, integration with adherence to the procedures and regulatory policies of the company, industry, government and law of the land, when incorporated in project governance with efficiency then we acquire the speed and best value for money
\end{abstract}

\section{Keywords}

Procurement, material management, ERP, information technology (IT) based, project systems

\section{INTRODUCTION}

In today's business scenario every process and system are to be optimized and the new technologies which are computer based have helped in optimizing these processes and systems. Procurement is an important part of business cycle and need to be optimized as other. The main challenges for a transparent, accountable, project procurement process in construction industry are information shortages in proper communication, lack of managerial experience, diversified buying practices and products and services range.

The main hurdle in implementing ethical behavior in project procurement is complexity of the different processes followed in various companies of construction industry. Simplification of all the process across the domain will help us in getting more optimized procurement processes across all segments as per buying behavior and products and services.

Buying behavior in the industry can be segmented by multiple, complex and diversified procurement policies. With advent of new technologies, new processes have been evolved as sources of availability and flow of data has increased. The trends show with more relevant data and its relevance, a decision can be better suited for any given condition. This has brought about a lot of changes and optimization in the traditional approach and has created different procurement process. Thus, with availability of more relevant data we can further optimize the processes and the system should be flexible enough to implement it.
Different practices that can be like Maverick buying which is, procurement of products and services without involving procurement department or competitive authority, may lead to increase in chaos and data unavailability, if not checked and regulated.

Products and services in the CRIP Industry varies from nuts and bolts to complex systems and equipment bringing all this into one process will make the process complex in nature and highly time consuming. Different attributes and recommendations of previous research work can be used to prepare a set of guidelines and choices to help the user to identify the best suited process along with that adequate space to optimize the process should be given to the user.

The system or the processes followed should be helping the user to take better decisions and also should relieve the users from taking straight forward decisions and proper automation may be used to do the same.

Enumerating the verticals, departments, sub-departments in the organizations and interconnecting them in a well-defined network for better performance of the organization as a whole needs detailed integration and linking of the processes followed by these intra organization bodies.

The procedures followed by different organizations and intraorganization bodies are guided by (i) The policies of the company (ii) Law of the land (iii) International regulations and (iv) Industrial practices. These, guidelines should be followed as closely as possible while purchasing. But, adequate flexibility with authorization should be provided to the user to take necessary decisions in case of emergency or while optimizing a process. Any systems which are designed to help the procuring team should be like it should follow the guidelines until and unless ordered otherwise with proper authorization.

Requirement of data and the use of those along with its own relevance are very important for any decision making. So, providing more and more relevant data to the user will enable them to make better decisions.

Recommendations and suggestions from different research work in the field can also be implemented after careful trail runs and simulations through the system will help us to check the efficiency of the said optimizations.

\section{PRE- CONDITIONS}

For designing the algorithm we have considered a few pre-conditions as mentioned below:

1. The software works on real time.

2. Every user has a unique ID and password. 
3. Every user is categorized by approval level (post or responsibilities as per the organization).

4. Material database and vendor database are present on the system and allowed to be read \& modify.

\section{THE PROCESS FLOW DIAGRAM} (Figure - I)

\subsection{The main process flow chart}

\section{Step 1: Identification of need}

The data requirement decision depends upon the need in any industry and also on various factors which are beyond the scope of algorithm. And hence it is left for the user to decide

\section{Step 2: Build or Buy}

Like above the variables and the data required to make this decision is outside the scope of this algorithm.

\section{Step 3: Preliminary Design \& Estimation}

Preliminary design \& estimation is done by planning, marketing, tendering groups involving feasibility studies, reading of technical specifications of a tender to estimate the cost.

This step though not done by the procurement department gives out an important data set i.e. next step preliminary Bill of Quantity (BOQ) and cost centers as per the said BOQ. Before moving on we have considered that it will be beneficial for any such algorithm* for planning, tendering and estimating to keep a similar step with an important data set of company policy and other legal and statutory aspects.

\section{Step 4: Preliminary BOQ and Cost Center}

The first base for any material management process involves analysis of material, solutions, systems, services, other expense (taxes \& duties, overheads, insurances, fees) and resources that includes man, money and equipment and assigns them to specific cost centers. But the BOQ and WBS created will be involve in various systems, solutions and services which may require further detailing and breaking down, for this scope will be provided in the software for the same with appropriate approvals as and when required by the algorithm and as per company policy. This step (step 4)can be called pre tendering estimation for client and contractor companies alike.

*Algorithm: A process or set of rules to be followed in calculations or other problem solving operation especially by a computer. Some contractors may use this step after issuing of tender document or RFQ (Request for Quotation) and some before as a part of business development.

Step 5: Review \& Approval of Preliminary BOQ and Cost Centers

This step (step 5) will be guided by the company policy and proper user accounts with necessary approvals as per the company policy can review, modify, approve, reject ask for more details and explanation or comment on the data set provided as per BOQ. These actions will be guided by company policy and other statutory requirements.

Step 6: Approve BOQ and Cost Centers
This data set will contain the details of the information gathered and process in step 4 and approve by competent user IDs as per company policy in step5.

In a contracting company this data set can be the information and data handed by, the marketing, tendering or any other department as approved by company policy as responsible for getting order from client over, to all the important departments like, project planning \& execution, design, finance, HR, legal \& any other department as per company policy if required, for further detailing and planning to execute the contract.

In a client type company this set can be the data approved by any department or individual assigned to verify the ideas and power to start the work.

As an output of this step (step 5) the software will generate a unique id and store this detail in the system as preliminary BOQ and cost centers as per the said BOQ.

This data is handed over to planning coordination and monitoring department or any other department performing such activities with primary responsibility of executing the job.

Other departments as stated above are given the necessary data which is needed to do the required job in their areas, with close link and data exchange systems with the primary responsible department. This will also include execution of work as instructed by planning department with clearance from proper approval level(s).

\section{Step 7: Planning coordination and monitoring}

The department responsible for planning, coordination and monitoring will chalk out the detail execution plan as per the data and information provided as above and collected by them during this step. This will include further detailing of systems, solution and specifications and of their respective cost centers to allocate funds to the new systems, materials, equipment, solutions, and resources as analyzed by the department.

Planning department will be helped by other department in this step and those departments will provide data set after completing the jobs as mentioned in previous point for proper execution of the project. These data will be uploaded in the system against the job number generated earlier, as modification and addition to the approved data set as in step5.

\section{Step 8: Review and Approval of Detailed Execution Plan}

The modified data set received from step 7 is reviewed and approved by user IDs which are authorized to do so by the company policy and is allowed by the software which proper approval levels. This approved data set is called detailed execution plan. This plan contains specifications, schedules, resources required and are handed over by the planning, coordination and monitoring department to detailed execution plan. This plan contains specifications, schedules; resources required and are handed over by the planning, co-ordination and monitoring department to different departments like design, HR, procurement, finance, execution and any other department as per company policy. The software will allow this by enabling setting different approval and access levels to different user ids.

Step 9: Data received by Procurement Department. 
The procurement department receives the materials services, solutions, systems, works with their individual cost centers and delivery date.

\section{Step 10: How to buy?}

The Procurement department uses a set company's policies, industrial experience and statutory obligations to decide upon the buying methods of each and every item of the BOQ. This step also includes to review and approval of such decisions by appropriate user ID's, the software will provide recommendations as per set company guidelines and will help the user to make the right decision.

\section{Step 11: Processes of Buying}

With the decision being made in step 9, the software will follow different processes of buying or sub algorithms to acquire the resources.

The culmination of this algorithm finishes with dividing of data set into two separate departments like finance and stores, which is beyond the scope of the paper, but we will be providing the data generated and fed into those project systems for smooth working of the organizations.

\section{SUB ALGORITHMS OR PROCUREMENT PROCESSES}

\subsection{E-tendering}

If this process is chosen by the user, after completing step 11 , then the inputs required by the software are specifications of the required item and its corresponding item code and WBS code in the master BOQ, stages of tendering, process should be followed by e.g. Traditional or reverse auctioning.
Depending on this data the system will guide the user to prepare the documents needed like notice inviting tender and pre qualifications as shown in the algorithm.

\subsection{Procurement through registered class approved vendors}

If procurement is to be done by registered and approved vendors, then Request for Quotations (RFQ) is sent and the process is followed as per the sub algorithm.

\subsection{Procurement through new vendor}

If the procurement is done by the new vendor then the vendor is to be registered first into the system. Thus modifying the vendor information sets in the data set. The process then moves on as per the sub- algorithm and provided.

\section{RECOMMENDATIONS AND CONCLUSIONS}

The above algorithm is formulated to increase data usage, transfer, sharing and analysis in preparation of a proper BOQ and cost centers, which is the primary for any procurement process which should be adopted by any standard organization. The said BOQ can be linked with material information sheet or material database to enable the user to access past data regarding specifications rates and other needed information to make a better decision.

The said database along with other database like vendor database, manpower database will be auto-saving databases recording every change with the initiators and authorizers of the change along with date and time of the change. This feature will enable transparency and accountability in the process. 


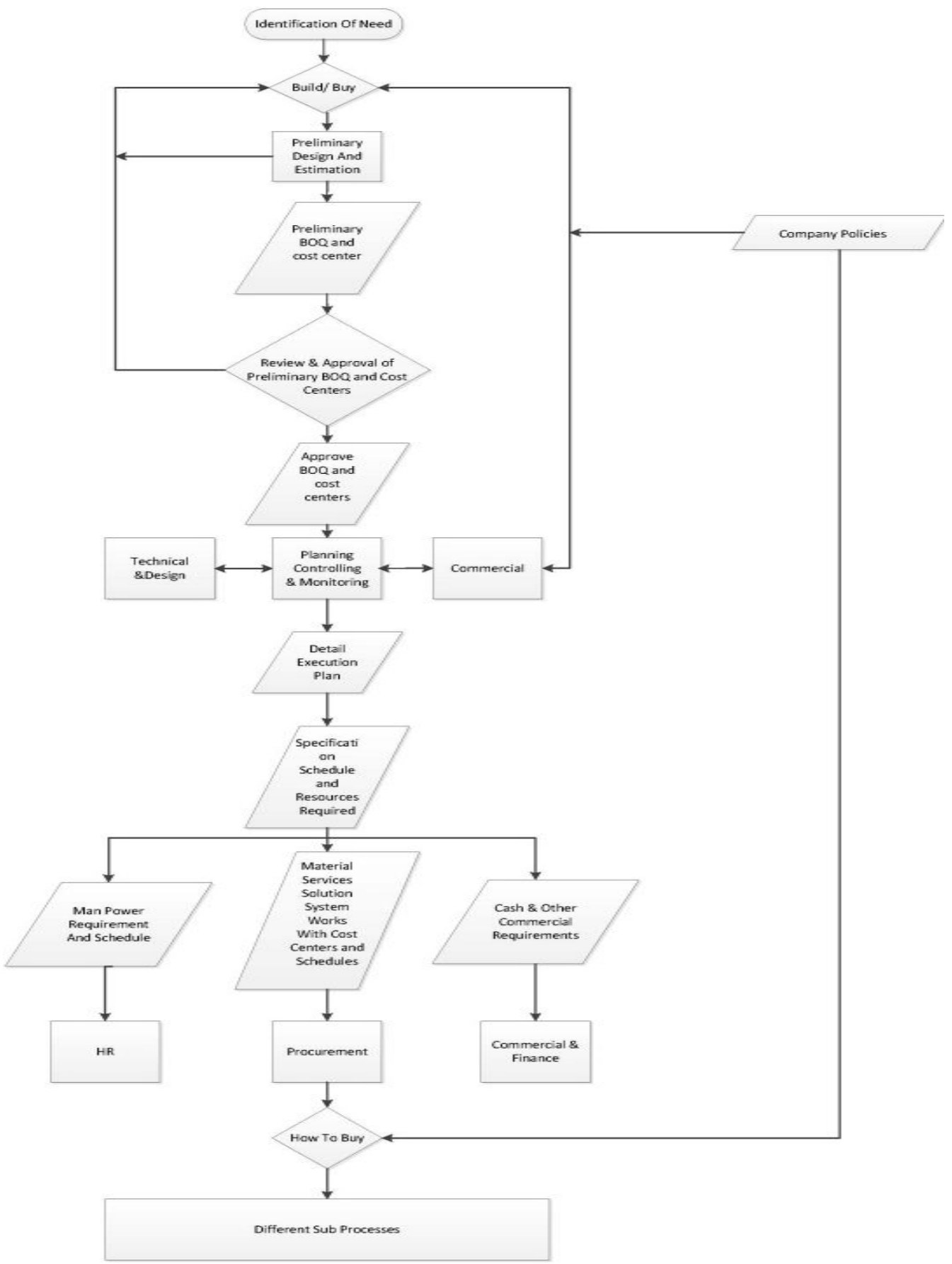

Figure - I

\section{REFRENCES}

[1] Aliza Abu Hassim, Project Governance : Ethical decision making in project procurement in the malaysian public sector

[2] Katri Karjalainen, Challenges of purchasing centralization, emprical evidence from public procurement

[3] Mikael Erikkson, Procurement of comlex technical systems, stratergies for successful projects.
[4] Bjarne Rerup Schlitcher,Pernille Kraemmergaard," A comprehensive literature review of the erp research field over na decade.

[5] PED Love,A Gunasekaran, H Li, "Concurrent engineering," a stratergy for procuring construction projects.

[6] Ram Singh, "Delays and cost overruns in infrastructure projects,"An enquiry into extends, causes and remedies.

[7] Antonio Davila,Mahendra Gupta,Richard.J Palmer, Moving procurement system to internet, The adoption and use of E-procurement technology models 
[8] Bernard Wieder, Peter Booth,Zoltan P.Matolcsy and Maria-Luise Ossimitz, The impact of erp system on firm and business process performance

[9] Charles Moller, ERP II,a conceptual framework for next generation enterprise sysytems

[10] Sherry Finney,Martin Corbett, ERP implementation, a complication and analysis of critical success factors

[11] Luis F.Alarcon,Rodrigo Rivas and Alfredo Serpell, Evaluation and improvement of the procurement processin construction projects

[12] Abhijeet Garekar, Dr.S.S.Pimplikar,Success and failure factors of indian construction companies.

[13] R.Preston McAFEE, John McMILLAN, Government procurement and international trade.

[14] Radia Benamghar,Atushi Iimi,Efficiency in public procurement in ruralroad projects of nepal.

[15] Richard A.Wysk,ISE 789 product and process engineering.
[16] Kennaeth K.L.Leung,IT research paper on ERP.

[17] Erik Fosser,Ole Hendrik Leister,Carl Erik Moe,Mike Newmen, ERP systems and advantages, some initial results.

[18] Juha Vehvilainen, Procurement in projectimplementation.

[19] Derek Walker,Steve Rowlinson,Procurement systems,a cross industry perspective.

[20] Tan Phat Nguyen,Nicholas Chileshe,Revising the critical factors causing failure of construction projects in Vietnam.

[21] Marwa a.Wardani,Comparng procurement for designbuild projects.

[22] Jakob Edler,Luke Georghiou,Public procurement and innovation, Resurrecting the demand side. 